\title{
Detection of Quantitative Trait Loci Affecting Twinning Rate in Israeli Holsteins by the Daughter Design
}

\author{
J. I. Weller, ${ }^{\star 1}$ M. Golik, ${ }^{*}$ E. Seroussi, ${ }^{*}$ M. Ron, ${ }^{*}$ and E. Ezra† \\ *Institute of Animal Sciences, ARO, The Volcani Center, Bet Dagan 50250, Israel \\ †Israel Cattle Breeders Association, Caesaria Industrial Park, Caesaria 38900, Israel
}

\begin{abstract}
Twinning rate was analyzed in the Israeli Holstein dairy cattle population by the multiple-trait animal model, and a daughter design genome scan for quantitative trait loci was performed. Each parity was considered a separate trait. Heritabilities of twinning rate were very low, but increased by parity from 0.01 in first parity to 0.03 in fifth parity. All genetic correlations among parities were $>0.77$, but all environmental correlations were $<0.07$. Genetic correlations between twinning rate and female fertility (measured as the inverse of the number of inseminations to conception) in the first 3 parities were negative for all 9 parity-by-trait combinations. All environmental correlations were very small, but generally negative. The overall genetic trend since 1985 was positive at $0.02 \%$ twinning/yr, whereas the phenotypic trends were positive for parities 3 and 4 and negative for the other parities, but all trends were quite small. A total of 5,221 cows, daughters of 11 sires, were genotyped for 73 markers spanning all 29 autosomes. There were 9 markers with significant effects on twinning rate at $P<0.05$, for a false discovery rate of 0.4 ; thus, about 5 of these probably represent true effects. Significant effects were found on chromosomes $1,6,7,8,14,15$, and 23 . Of these, 3 effects were significant at $P<0.01$, for a false discovery rate of 0.24 . All 11 families were analyzed by interval mapping of chromosome 7 . Only 2 families showed nominally significant effects, but chromosome-wise significance at $P$ $<0.05$ was not obtained for either family. Suggestive evidence of quantitative trait loci near the beginning of the chromosome and near position $50 \mathrm{cM}$ were found in both families. Sire 3070 also had a significant effect for female fertility near the beginning of the chromosome. There was also evidence for a third quantitative trait loci at the end of the chromosome for sire 2357.
\end{abstract}

Key words: twinning rate, multiple-trait animal model, quantitative trait loci, genetic analysis

Received December 4, 2007.

Accepted February 27, 2008

${ }^{1}$ Corresponding author: weller@agri.huji.ac.il

\section{INTRODUCTION}

Twinning rate in dairy cattle is a quantitative trait with low heritability (Johanson et al., 2001). Most studies that have considered the economic value of twinning in dairy cattle have concluded that increased twinning rate is economically undesirable, because increased twinning rate reduces cow reproductive performance and increases risk for dystocia, retained placenta, abortion, and early embryonic loss (summarized by Cobanoglu et al., 2005). Increased twinning rate may be desirable for beef cattle under appropriate management systems (Gregory et al., 1996). Because twinning rate is a dichotomous trait with a low frequency for one category, various studies have proposed analysis by the threshold model (e.g., Ron et al., 1990). In this case, genetic evaluations are derived for sires but not cows. Analysis is further complicated by the fact that mean twinning rate increases with parity and heritabilities may be different in different parities. Genetic correlations among parities have only been estimated between first and second parity (Karlsen et al., 2000), but not for Holsteins.

Partial or complete genome scans for QTL affecting twinning rate have been performed for North American Holsteins (Cruickshank et al., 2004; Cobanoglu et al., 2005) and Norwegian cattle (Lien et al., 2000). In both cases granddaughter designs (Weller et al., 1990) were performed. In the Holstein analyses (Cruickshank et al., 2004; Cobanoglu et al., 2005) EBV derived by a threshold model were analyzed, while in the analysis of Norwegian cattle (Lien et al., 2000) the trait analyzed was average first-parity twinning rate corrected for fixed effects. All of these studies have genotyped relatively small samples of animals with respect to the sample sizes required to obtain reasonable power to detect QTL of moderate size by the granddaughter design (Weller et al., 1990). The analysis of Holsteins included 586 sons from 20 grandsire families, for an average of 29 sons per sire, whereas the Norwegian study included 285 sons from 6 grandsire families. Thus, it is not surprising that no QTL with genomewise significance were detected. Only one effect on Bos 
taurus autosome (BTA) 5 reached the $10 \%$ genome-wise significance level in the Norwegian population (Lien et al., 2000). A nominal $P$-value $<0.01$ was obtained using combined linkage and linkage disequilibrium mapping (Meuwissen et al., 2002).

Although the granddaughter design is more powerful than the daughter design per individual genotyped, many more cows are available for genotyping compared with bulls with genetic evaluations based on samples of daughters. Furthermore, in both designs for an equal number of genotypes, power is increased with analysis of a few large families compared with many small families. Ron et al. (2004) analyzed the Israeli Holstein population by a daughter design based on genotypes of 5,221 cows from 11 sire families. Based on the equations of Weller et al. (1990), and assuming a heritability of 0.05 , for an equal number of markers this design is approximately as powerful as the Norwegian study, but less powerful than the North American Holstein study.

Application of the daughter design to analyze twinning rate requires genetic evaluations for the individual cows. These are not computed by a sire model, but can be computed by an animal model. Because both genetic and environmental variances are likely to be different in different parities, the multiple-trait animal model, which considers each parity as a separate trait, is most appropriate for obtaining individual cow evaluations, provided that the genetic correlations among the parities are high (Weller and Ezra, 2004).

The objectives of this study were 1) to estimate variance and covariance components for twinning rate, considering first through fifth parities; 2) to compute genetic evaluations for twinning rate for the entire milkrecorded Israeli Holstein population; 3) to estimate genetic and environmental trends for twinning rate; 4) to estimate genetic and environmental correlations between twinning rate and other economically important traits, including conception rate; and 5) to detect and analyze QTL affecting twinning rate by application of the daughter design.

\section{MATERIALS AND METHODS}

\section{Genetic Analysis of Twinning Rate}

Three data sets of phenotypic records on twinning were analyzed. Data set 1 , the complete data set, consisted of 1,729,055 first- through fifth-parity calving records of 671,361 cows from 1,293 herds with first calving date between January 1, 1985, and March 31, 2007. This data set was used to compute genetic evaluations for all animals, and to compute phenotypic and genetic trends. Records were deleted if sire was unknown, if freshening year - birth year - parity $>3$, or if the first-parity record was missing. Later-parity re-
Table 1. Number of records and levels of effects in the 3 data sets

\begin{tabular}{lrrr}
\hline & \multicolumn{3}{c}{ Data set $^{1}$} \\
\cline { 2 - 4 } Item & \multicolumn{1}{c}{1} & \multicolumn{1}{c}{2} & \multicolumn{1}{c}{3} \\
\hline Records, n & $1,729,055$ & 66,210 & 53,765 \\
Animals with records, $\mathrm{n}$ & 671,361 & 66,210 & 53,765 \\
Ancestors without records, n & 81,323 & 73,647 & 64,549 \\
Herd-year-seasons, n & 67,186 & 14,214 & 12,954 \\
Genetic groups, n & 63 & 2 & 2 \\
\hline
\end{tabular}

${ }^{1}$ Variance components were assumed known for data set 1 , and estimated from the data by REML for data sets 2 and 3 .

cords were included only if there were valid records for all previous parities. For each herd-year, 2 seasons were defined: calvings between April and September, and calvings between October and March. There were a total of 67,186 herd-year-seasons (HYS). In addition, all parents and grandparents of cows with records were included in the animal model analysis. Details of data set 1 are given in Table 1 . Number of records and twinning rate means by parity are given in Table 2 . Similar to the results of Johanson et al. (2001) for North American Holsteins, twinning rate increased from $1 \%$ in first parity to $7.3 \%$ in fifth parity.

Data set 2 is a subset of data set 1 that was used for estimation of variance and covariance components among the parities. This data set included 66,210 cows with first calvings since 1991 and valid birth records for all 5 parities. As in data set 1, all parents and grandparents of cows with birth records were included in the analysis. For this data set HYS were defined as in data set 1 , but only relative to first parity. Details of this data set are also given in Table 1 . Data set 3 was generated to estimate covariance components between twinning rate and female fertility in the first 3 parities. This data set included all animals in data set 2 with valid female fertility records for parities 1 through 3 . Female fertility was defined as the inverse of the number of inseminations to conception. For cows that did not conceive, the expected number of conceptions is computed (Weller and Ezra, 1997). As in the first 2 data sets, all parents and grandparents of cows with birth records were included in the analysis, and HYS were defined relative

Table 2. Mean and standard deviation of twinning rate by parity in data set 1

\begin{tabular}{lccc}
\hline & & \multicolumn{2}{c}{ Twins, \% } \\
\cline { 3 - 4 } Parity & Records, $n$ & Mean & SD \\
\hline 1 & 671,391 & 1.00 & 10.00 \\
2 & 460,940 & 4.33 & 20.36 \\
3 & 304,213 & 6.61 & 24.85 \\
4 & 188,077 & 7.24 & 25.92 \\
5 & 104,434 & 7.35 & 26.10 \\
\hline
\end{tabular}


Table 3. Heritabilities (on the diagonal), genetic correlations (above the diagonal), and environmental correlations (below the diagonal) for twinning rate by parity, data set 2

\begin{tabular}{lccccc}
\hline Parity & 1 & 2 & 3 & 4 & 5 \\
\hline 1 & $\mathbf{0 . 0 1 3}$ & 0.805 & 0.793 & 0.784 & 0.774 \\
2 & 0.031 & $\mathbf{0 . 0 2 2}$ & 0.876 & 0.927 & 0.957 \\
3 & 0.023 & 0.051 & $\mathbf{0 . 0 2 4}$ & 0.957 & 0.945 \\
4 & 0.027 & 0.053 & 0.049 & $\mathbf{0 . 0 2 6}$ & 0.977 \\
5 & 0.019 & 0.045 & 0.051 & 0.061 & $\mathbf{0 . 0 3 1}$ \\
\hline
\end{tabular}

to the first parity records. Details of this data set are also given in Table 1.

The analysis model for all 3 data sets was:

$$
\mathrm{T}_{\mathrm{ijklm}}=\mathrm{G}_{\mathrm{ij}}+\mathrm{A}_{\mathrm{ik}}+\mathrm{H}_{\mathrm{il}}+\mathrm{e}_{\mathrm{ijklm}}
$$

where $\mathrm{T}_{\mathrm{ijk} k \mathrm{~m}}=$ the $\mathrm{mth}$ record of cow $\mathrm{k}$ from herd $\mathrm{l}$ for trait $\mathrm{i} ; \mathrm{G}_{\mathrm{ij}}=$ the $\mathrm{jth}$ genetic group effect for animals with unknown parents, $A_{\mathrm{ik}}=$ is the additive genetic effect of cow $\mathrm{k}$ for trait $\mathrm{i}, \mathrm{H}_{\mathrm{il}}=$ the effect of HYS $\mathrm{l}$ on trait $i$, and $\mathrm{e}_{\mathrm{ijklm}}=$ the random residual effect; $\mathrm{G}$ and HYS effects were fixed, the other effects were random. Two genetic groups were defined for data sets 2 and 3 , depending on which parents were unknown: group 1 for animals with only the dam unknown, and group 2 for animals with sire or both parents unknown. For data sets 1 and 2 the traits were the birth type for each parity: 0 for single birth and 1 for twin birth. For data set 3 the traits were the birth type and female fertility score for parities 1 through 3 .

All variance and covariance components were computed by the MTC REML multitrait animal model program (I. Misztal, Univ. Georgia, Athens; personal communication). This program requires valid records for all traits on animals with trait records. For analysis of data set 1 the variance components derived from the analysis of data set 2 were used. A total of 63 groups were determined based on sex of animal with unknown parents, on which parents were unknown, on year of birth, and on breed of sire if not Holstein. The overall EBV for twinning rate was computed as the mean of the 5 individual parity EBV for each animal. Reliabilities of the EBV were estimated using the algorithm of Misztal and Wiggans (1988), as corrected by Misztal et al. (1991). This algorithm assumes a single-trait animal model. Thus, the reliabilities are only approximate for the multiple-trait animal model.

Genetic trends for each parity and the overall EBV for twinning rate were computed as the regression of EBV on the cows' birth year. Phenotypic trends were computed in a similar manner for twinning rate for each parity. Correlations were computed between sire overall EBV for twinning rate and the other economic traits with genetic evaluations: milk, fat, and protein yields; SCS; female fertility; milk yield persistency; herd life; dystocia and calf mortality (both as a trait of the sire of the calf, direct effect, and as a trait of the sire of the cow, maternal effect); and the Israeli selection index, PD07 (Weller and Ezra, 2006). For each pair of traits, correlations were computed only for bulls with reliabilities $>0.5$ for both traits.

\section{Genotyping Methods}

From 1995 through 1999, blood samples were collected in 233 herds from approximately 13,000 IsraeliHolstein cows, putative daughters of 11 sires. Three to $5 \mathrm{~mL}$ of blood from the jugular vein of cows was collected using vacutainer tubes with heparin anticoagulant (Becton Dickinson, Franklin Lakes, NJ). Frozen semen of the 11 Israeli-Holstein sires was obtained from the Sion AI Institute (Shikmim, Israel). The DNA from frozen blood or semen was extracted by the salting-out procedure (Ma et al., 1996). Eleven Israeli-Holstein families including 5,221 cows were analyzed by a daughter design for twinning rate. Cows with invalidated paternity as described by Weller et al. (2004) or without genetic evaluations were deleted from further analysis. The cows were genotyped for 73 microsatellites with maximum spacing between markers of $53 \mathrm{cM}$. The map locations and number of animals genotyped for each marker are given in Ron et al. (2004). The mean number of sires genotyped per marker was 8.6 , and the mean number of heterozygous sires was 5.9. Thus, the mean frequency

Table 4. Heritabilities (on the diagonal), genetic correlations (above the diagonal), and environmental correlations (below the diagonal) for twinning rate and female fertility by parity, data set 3

\begin{tabular}{|c|c|c|c|c|c|c|c|}
\hline \multirow[b]{2}{*}{ Trait } & \multirow[b]{2}{*}{ Parity } & \multicolumn{3}{|c|}{ Twinning rate } & \multicolumn{3}{|c|}{ Female fertility } \\
\hline & & 1 & 2 & 3 & 1 & 2 & 3 \\
\hline \multirow[t]{3}{*}{ Twinning rate } & 1 & 0.012 & 0.890 & 0.925 & -0.278 & -0.159 & -0.127 \\
\hline & 2 & 0.029 & 0.022 & 0.816 & -0.270 & -0.366 & -0.284 \\
\hline & 3 & 0.014 & 0.041 & 0.021 & -0.369 & -0.195 & -0.113 \\
\hline \multirow[t]{3}{*}{ Fertility } & 1 & -0.014 & -0.025 & -0.015 & 0.018 & 0.874 & 0.861 \\
\hline & 2 & -0.002 & -0.027 & -0.015 & 0.048 & 0.016 & 0.971 \\
\hline & 3 & 0.001 & -0.014 & -0.038 & 0.043 & 0.053 & 0.018 \\
\hline
\end{tabular}


Table 5. Genetic and phenotypic trends for twinning rate, data set 1

\begin{tabular}{lcc}
\hline Trend & Parity & Trend $(\% / y r)$ \\
\hline Phenotypic & 1 & -0.003 \\
& 2 & $-0.014^{* * *}$ \\
& 3 & $0.029^{* * *}$ \\
4 & $0.026^{*}$ \\
Genetic & 5 & $-0.058^{* * *}$ \\
& 1 & $0.006^{* * *}$ \\
& 2 & $0.020^{* * *}$ \\
& 3 & $0.023^{* * *}$ \\
4 & $0.027^{* * *}$ \\
& 5 & $0.032^{* * *}$ \\
& All & $0.022^{* * *}$ \\
\hline
\end{tabular}

$* P<0.05 ; * * P<0.01 ; * * * P<0.001$

of heterozygous sires among genotyped sires was $69 \%$. Of the readable genotypes, 110,558 genotypes were for cows that were daughters of heterozygous sires $(68 \%)$. Genotypes were considered informative if the daughter genotype was different from her sire's genotype (Ron et al., 1995). Of the genotypes of daughters of heterozygous sires, 86,304 genotypes were informative $(78 \%$ of the genotypes of heterozygous sires, and $50 \%$ of all readable genotypes). The average number of informative genotypes per marker was 1,182.

\section{QTL Detection and Analysis}

Preliminary analysis was by ANOVA of the cows' genetic evaluations for each trait, with the marker effect nested within sire. Because of the large number of comparisons, nominal significance values are not relevant. The false discovery rate (FDR) computed at nominal significance values of 0.05 and 0.01 was therefore used to determine the fraction of actual segregating QTL among those deemed nominally significant (Benja-

Table 6. Correlations between EBV for twinning rate and economically important traits derived from data set 1 for bulls with reliability $>0.5$

\begin{tabular}{lcc}
\hline Trait $^{1}$ & Correlation & Bulls, n \\
\hline Milk & $0.155^{* * *}$ & 1,153 \\
Fat & $0.112^{* * *}$ & 1,153 \\
Protein & $0.190^{* * *}$ & 1,153 \\
SCS & $0.077^{* *}$ & 1,153 \\
Female fertility & $-0.143^{* * *}$ & 1,150 \\
Milk persistency & -0.010 & 1,153 \\
Herd life & -0.039 & 1,092 \\
PD07 & $0.108^{* * *}$ & 1,092 \\
Dystocia, MGS & $0.072^{*}$ & 1,092 \\
Calf mortality, MGS & 0.007 & 1,092 \\
Dystocia, sire & $0.147^{*}$ & 256 \\
Calf mortality, sire & 0.030 & 256 \\
\hline
\end{tabular}

${ }^{1} \mathrm{PD} 07$ = Israeli selection index; MGS = maternal grandsire.

$* P<0.05 ; * * P<0.01 ; * * * P<0.001$. mini and Hochberg, 1995). Significant effects were found for a large number of traits on BTA7, including female fertility (Weller et al., 2008). Therefore, additional markers were genotyped on this chromosome for the families with significant contrasts. Interval mapping, taking into account missing or uninformative genotypes, was therefore performed on this chromosome for all 11 families (Knott et al., 1996). Chromosomewise significance levels were determined by permutation analysis (Churchill and Doerge, 1994). Two hundred permutation samples were generated, and the empirical 0.05 significance levels were compared with the nominal $F$-value probabilities.

\section{RESULTS AND DISCUSSION}

Heritabilities, genetic correlations, and environmental correlations for twinning rate by parity are given in Table 3. As all previous studies show, heritability of twinning rate by linear model analysis was low, but increased by parity (Ron et al., 1990; Karlsen et al., 2000; Lien et al., 2000; Johanson et al., 2001). All genetic correlations were $>0.77$, but all environmental correlations were $<0.07$. Thus, use of a multiple-trait animal model is justified. Karlsen et al. (2000) found a genetic correlation of unity between first and second parities for Norwegian cattle. Heritabilities, genetic correlations, and environmental correlations for twinning rate and female fertility by parity for parities 1 through 3 are given in Table 4 . Genetic correlations across parity for each trait were high and positive, whereas genetic correlations between the 2 traits were negative for all 9 trait-by-parity combinations. The between-trait correlation with the highest absolute value $(-0.369)$ was between first-parity fertility and thirdparity twinning rate. Contrary to previous results that found negative phenotypic relationships between fertility and twinning rate (summarized by Cobanoglu et al., 2005), the absolute values of all environmental correlations were very low, but correlations were generally negative.

Genetic and phenotypic trends for twinning rate in the analysis of data set 1 are given in Table 5 for the individual parities. The overall genetic trend is also given. All genetic trends were positive and increased with increase in parity, whereas the phenotypic trends were positive for parities 3 and 4 and negative for the other parities, but all trends were quite small. The overall genetic trend was positive at $0.02 \%$ twinning/yr. Karlsen et al. (2000) found that both phenotypic and genetic trends were positive for Norwegian cattle.

Correlations between EBV for twinning rate and economically important traits for bulls with reliability $>0.5$ are given in Table 6. Correlations were positive for milk 
TWINNING RATE IN ISRAELI HOLSTEINS

Table 7. Significant marker effects associated with twinning rate, nominal $P<0.05$

\begin{tabular}{|c|c|c|c|c|c|c|}
\hline \multirow[b]{2}{*}{ Marker } & \multicolumn{2}{|c|}{ Position } & \multirow{2}{*}{$\begin{array}{l}\text { Heterozygous } \\
\text { sires, } \mathrm{n}\end{array}$} & \multirow{2}{*}{$\begin{array}{l}\text { Informative } \\
\text { daughters, } n\end{array}$} & \multirow{2}{*}{$\begin{array}{c}\text { Families with } \\
\text { significant } \\
\text { contrasts, } \mathrm{n}\end{array}$} & \multirow[b]{2}{*}{$F$ probability } \\
\hline & Chromosome & $\mathrm{cM}$ & & & & \\
\hline BM1824 & 1 & 108.6 & 6 & 1,265 & 2 & 0.0312 \\
\hline BMS518 & 6 & 55.2 & 2 & 536 & 1 & 0.0019 \\
\hline BM415 & 6 & 76.3 & 8 & 1,581 & 1 & 0.0375 \\
\hline RM6 & 7 & 25.4 & 4 & 761 & 1 & 0.0031 \\
\hline ILSTS006 & 7 & 116.6 & 8 & 2,055 & 2 & 0.0307 \\
\hline BMS1341 & 8 & 51.4 & 5 & 1,096 & 1 & 0.0196 \\
\hline BM4305 & 14 & 66.4 & 3 & 543 & 1 & 0.0406 \\
\hline SPS115 & 15 & 70.0 & 4 & 589 & 2 & 0.0450 \\
\hline CYP21 & 23 & 67.0 & 4 & 808 & 1 & 0.0085 \\
\hline
\end{tabular}

yield traits, PD07, SCS, and dystocia both as sire of cow and calf. However, positive values are economically unfavorable for SCS and dystocia. Correlations with calf mortality were not significant either as sire of cow or calf. Correlations with fertility, persistency, and herd life were all negative. The results for dystocia correspond to previous studies (Cobanoglu et al., 2005), and the results for female fertility correspond to the REML analysis results in Table 4.

There were 9 markers with significant effects on twinning rate at $P<0.05$, for an FDR of $73 \times 0.05 / 9=$ 0.4 ; thus, about 5 of these contrasts probably represent segregating QTL. These effects are listed in Table 7. Significant effects were found on chromosomes 1, 6, 7, $8,14,15$, and 23 . Of these, 3 effects were significant at $P<0.01$, for an FDR of 0.24. Bos taurus autosomes 6 and 7 showed evidence for 2 significant effects each. Two previous studies also found evidence for segregating QTL for twinning rate on BTA 5, 7, and 23 (Lien et al., 2000; Cruickshank et al., 2004), whereas Cobanoglu et al. (2005) found evidence for segregating QTL on BTA 8 and 14. Thus, only the effects on BTA 1,6 , and 15 were not previously reported, and the effects on BTA 1 and 15 were only marginally significant at $P<$ 0.05 . However, the locations of the QTL detected previously on BTA 7 and 8 do not correspond to the locations of significant effects found in the current analysis (http://www.animalgenome.org/cgi-bin/QTLdb/BT/ draw_traitmap?trait_ID = 1078).

All 11 families were analyzed by interval mapping of BTA 7, but only 2 sire families showed significant effects (sire families 2357 and 3070). Location of maximum test statistics, test statistic values, QTL substitution effects, and nominal probability values are given in Table 8 for these families, and the test statistic profiles are shown in Figure 1. Both families give evidence of QTL near the beginning of the chromosome and near position $50 \mathrm{cM}$. Of these 2 sires, only 3070 also had a significant effect for female fertility near the beginning of the chromosome, but the other 4 families with significant contrasts for fertility did not display significant effects for twinning rate (Weller et al., 2008). Thus, it is unlikely that the same QTL affects both traits. There was also evidence for a third QTL at the end of the chromosome for sire 2357.

Nominal $F$ probabilities for the test statistic maxima were 0.017 and 0.010 . The QTL substitution effects were 0.25 and $0.22 \%$ twinning, but because the dependent variable was the cows' genetic evaluations and twinning rate has very low heritability, these values underestimate the actual QTL effects (Israel and Weller, 1998). Neither family was significant at the 0.05 chromosome-wise level by permutation test. The 0.05 chromosome-wise critical value of the test statistic was 8.3 for sire 3070 . Thus, although the FDR results indicate that QTL for twinning rate are segregating in the population, no QTL can be considered verified at this point.

\section{CONCLUSIONS}

Heritability of twinning rate increased from 0.01 in first parity to 0.03 in fifth parity. All genetic correlations were $>0.77$, but all environmental correlations were $<0.07$, thus the multiple-trait animal model is appropriate. Genetic correlations between twinning rate and female fertility in the first 3 parities were negative for all combinations. All environmental correlations were very low, but generally negative. The genetic trend was positive at $0.022 \%$ twinning/yr. Of 73 markers analyzed there were 9 markers with significant effects on twinning rate at $P<0.05$ for a false discovery rate of 0.4 ; thus, about 5 of these contrasts probably represent seg-

Table 8. Location of maximum test statistics, test statistic values, QTL substitution effects, and nominal probability values for the families with significant contrasts for twinning rate on chromosome 7

\begin{tabular}{cccccc}
\hline Sire & $\begin{array}{c}\text { Daughters, } \\
\mathrm{n}\end{array}$ & $\begin{array}{c}\text { Position } \\
(\mathrm{cM})\end{array}$ & $\begin{array}{c}\text { Test } \\
\text { statistic }\end{array}$ & $\begin{array}{c}\text { Substitution } \\
\text { effect }\end{array}$ & $\begin{array}{c}\text { Nominal } \\
\text { probability }\end{array}$ \\
\hline 2357 & 582 & 58 & 5.7 & 0.25 & 0.017 \\
3070 & 686 & 42 & 6.6 & 0.22 & 0.010 \\
\hline
\end{tabular}




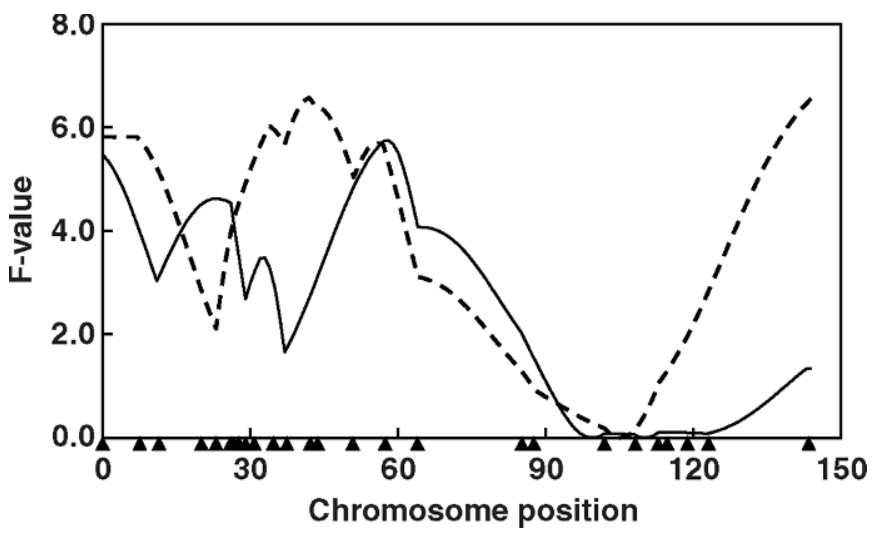

Figure 1. Interval mapping for twinning rate on Bos taurus autosome (BTA) 7. Solid line indicates sire 2357, the dashed line, sire 3070. Positions (cM) of markers are indicated by arrows.

regating QTL. Significant effects were found on chromosomes $1,6,7,8,14,15$, and 23 . Of these, 3 effects were significant at $P<0.01$. Evidence of QTL near the beginning of BTA 7 and near position $50 \mathrm{cM}$ were found by interval mapping in 2 families. Chromosome-wise significance was not obtained for either family.

\section{ACKNOWLEDGMENTS}

This research was supported by grants from the Israel milk marketing board and the European Sixth Research and Technological Development Framework Programme, Proposal No. 016250-2 SABRE. We thank R. Spelman (Livestock Improvement Corp., Hamilton, New Zealand) for use of his interval mapping program, and I. Misztal (University of Georgia, Athens) for use of the MTC REML program.

\section{REFERENCES}

Benjamini, Y., and Y. Hochberg. 1995. Controlling the false discovery rate: A practical and powerful approach to multiple testing. J. R. Stat. Soc. Ser. B. 57:289-300.

Churchill, G. A., and R. W. Doerge. 1994. Empirical threshold values for quantitative trait mapping. Genetics 138:963-971.

Cobanoglu, O., P. J. Berger, and B. W. Kirkpatrick. 2005. Genome screen for twinning rate QTL in four North American Holstein families. Anim. Genet. 36:303-308.

Cruickshank, J., M. R. Dentine, P. J. Berger, and B. W. Kirkpatrick. 2004. Evidence for quantitative trait loci affecting twinning rate in North American Holstein cattle. Anim. Genet. 35:206-212.

Gregory, K. E., S. E. Echternkamp, and L. V. Cundiff. 1996. Effects of twinning on dystocia, calf survival, calf growth, carcass traits, and cow productivity. J. Anim. Sci. 74:1223-1233.
Israel, C., and J. I. Weller. 1998. Estimation of candidate gene effects in dairy cattle populations. J. Dairy Sci. 81:1653-1662.

Johanson, J. M., P. J. Berger, B. W. Kirkpatrick, and M. R. Dentine. 2001. Twinning rates for North American Holstein sires. J. Dairy Sci. 84:2081-2088.

Karlsen, A., J. Ruane, G. Klemetsdal, and B. Heringstad. 2000. Twinning rate in Norwegian cattle: Frequency (co)variance components, and genetic trends. J. Anim. Sci. 78:15-20.

Knott, S. A., J. M. Elsen, and C. S. Haley. 1996. Methods for multiplemarker mapping of quantitative trait loci in half-sib populations. Theor. Appl. Genet. 93:71-80.

Lien, S., A. Karlsen, G. Klemetsdal, D. I. Vage, I. Olsaker, H. Klungland, M. Aasland, B. Heringstad, J. Ruane, and L. Gomez-Raya. 2000. A primary screen of the bovine genome for quantitative trait loci affecting twinning rate. Mamm. Genome 11:877-882.

Ma, R. Z., J. E. Beever, Y. Da, C. A. Green, I. Russ, C. Park, D. W. Heyen, R. E. Everts, S. R. Fisher, K. M. Overton, A. J. Teale, S. J. Kemp, H. C. Hines, G. Guerin, and H. A. Lewin. 1996. A male linkage map of the cattle (Bos taurus) Genome. J. Hered. 87:261-271.

Meuwissen, T. H. E., A. Karlsen, S. Lien, I. Olsaker, and M. E. Goddard. 2002. Fine mapping of a quantitative trait locus for twinning rate using combined linkage and linkage disequilibrium mapping. Genetics 161:373-379.

Misztal, I., T. J. Lawlor, T. H. Short, and G. R. Wiggans. 1991. Continuous genetic evaluation of Holstein for type. J. Dairy Sci. 74:2001-2009.

Misztal, I., and G. R. Wiggans. 1988. Approximation of prediction error variance in large-scale animal models. J. Dairy Sci. 71(Suppl. 2):27-32.

Ron, M., E. Ezra, and J. I. Weller. 1990. Genetic analysis of twinning rate in the Israeli Holstein cattle. Genet. Sel. Evol. 22:349-359.

Ron, M., H. A. Lewin, Y. Da, M. Band, A. Yanai, Y. Blank, E. Feldmesser, and J. I. Weller. 1995. Prediction of informativeness for microsatellite markers among progeny of sires used for detection of economic trait loci in dairy cattle. Anim. Genet. 26:439-441.

Ron, M., E. Feldmesser, M. Golik, I. Tager-Cohen, D. Kliger, V. Reiss, R. Domochovsky, O. Alus, E. Seroussi, E. Ezra, and J. I. Weller. 2004. A complete genome scan of the Israeli Holstein population for quantitative trait loci by a daughter design. J. Dairy Sci. $87: 476-490$

Weller, J. I., and E. Ezra. 1997. Genetic analysis of somatic cell concentration and female fertility of Israeli Holsteins by the individual animal model. J. Dairy Sci. 80:586-593.

Weller, J. I., and E. Ezra. 2004. Genetic analysis of the Israeli Holstein dairy cattle population for production and non-production traits with a multitrait animal model. J. Dairy Sci. 87:1519-1527.

Weller, J. I., and E. Ezra. 2006. Difficult calving and calf mortality in the breeding index. Meshek Habakar Vehahalav 325:53-55. (In Hebrew).

Weller, J. I., E. Feldmesser, M. Golik, I. Tager-Cohen, R. Domochovsky, O. Alus, E. Ezra, and M. Ron. 2004. Factors affecting incorrect paternity assignment in the Israeli Holstein population. J. Dairy Sci. 87:2627-2640

Weller, J. I., M. Golik, S. Reikhav, R. Domochovsky, E. Seroussi, and M. Ron. 2008. Detection and analysis of QTL affecting production and secondary traits on chromosome 7 in Israeli Holsteins. J. Dairy Sci. 91:802-813.

Weller, J. I., Y. Kashi, and M. Soller. 1990. Power of "daughter" and "granddaughter" designs for genetic mapping of quantitative traits in dairy cattle using genetic markers. J. Dairy Sci. 73:2525-2537. 